\title{
Dental Metric Assessment of the Omo Fossils: Implications for the Phylogenetic Position of Australopithecus africanus
}

\author{
KEVIN HUNT AND VIRGINIA J. VITZTHUM \\ Department of Anthropology, University of Michigan, Ann Arbor, \\ Michigan 48109
}

KEY WORDS Hypermasticatory, Homo, Australopithecus afarensis

\begin{abstract}
The discovery of Australopithecus afarensis has led to new interpretations of hominid phylogeny, some of which reject $A$. africanus as an ancestor of Homo. Analysis of buccolingual tooth crown dimensions in australopithecines and Homo species by Johanson and White (Science 202:321-330, 1979) revealed that the South African gracile australopithecines are intermediate in size between Laetoli/Hadar hominids and South African robust hominids. Homo, on the other hand, displays dimensions similar to those of $A$. afarensis and smaller than those of other australopithecines. These authors conclude, therefore, that $A$. africanus is derived in the direction of $A$. robustus and is not an ancestor of the Homo clade. However, there is a considerable time gap (ca. 800,000 years) between the Laetoli/Hadar specimens and the earliest Homo specimens; "gracile" hominids from Omo fit into this chronological gap and are from the same geographic area. Because the early specimens at Omo have been designated $A$. afarensis and the later specimens classified as Homo habilis, Omo offers a unique opportunity to test hypotheses concerning hominid evolution, especially regarding the phylogenetic status of $A$. africanus. Comparisons of mean cheek teeth breadths disclosed the significant $(\mathrm{P} \leqslant 0.05)$ differences between the Omo sample and the Laetoli/Hadar fossils $\left(\mathrm{P}_{4}, \mathrm{M}_{2}\right.$, and $\left.\mathrm{M}^{3}\right)$, the Homo fossils $\left(\mathrm{P}_{3}, \mathrm{P}_{4}, \mathrm{M}_{1}, \mathrm{M}_{2}\right.$, and $\left.\mathrm{M}^{1}\right)$, and $A$. africanus $\left(M_{3}\right)$. Of the several possible interpretations of these data, it appears that the high degree of similarity between the Omo sample and the South African gracile australopithecine material warrants considering the two as geographical variants of $A$. africanus. The geographic, chronologic, and metric attributes of the Omo sample argue for its lineal affinity with A. afarensis and Homo. In conclusion, a consideration of hominid postcanine dental metrics provides no basis for removing $A$. africanus from the ancestry of the Homo lineage.
\end{abstract}

The discovery and naming of a new species of australopithecine, Australopithecus afarensis, (Johanson et al., 1978) has provided paleontologists with a new and unique perspective on Pliocene hominid evolution. Based on their interpretation of these fossils, the discoverers and their colleagues have advanced a new phylogenetic interpretation of hominid evolution (Johanson and White, 1979; Johanson, 1980; White et al., 1981) in which $A$. afarensis is the only known hominid ancestor of the Homo clade; other australopithecine species, including Australopithecus africanus, are relegated to deadend side branches. In this vein, Johanson and
White (1979:327) argue that South African gracile specimens "share several distinctive, derived characters with later robust australopithecines" which exclude $A$. africanus from the ancestry of the Homo lineage. White et al. (1981:467) state:

For South African A. africanus to be considered a common ancestor for both later hominid clades it is necessary to postulate an evolutionary reversal [italics ours] involving many functionally related characters of an established morphological and adap-

Received May 28, 1985; accepted May 16, 1986. 
tive complex. The derived characters of the mandible, face and dentition in $A$. africanus would necessarily have been evolved from the A. afarensis condition and then been lost again in a relatively late transition to Homo habilis.

Although White, Johanson, and colleagues (Johanson and White, 1979; White et al., 1981; Kimbel, 1984; Kimbel et al,, 1984; Kimbel and Rak, 1985) have been careful to point out that morphological features serve as the most important bases for their taxonomic and phylogenetic assessment, they also contend that "dental metrics reinforce the hypothesis that the [A. africanus specimens] represent a link between the basal, undifferentiated hominids at Hadar and Laetolil and the later robust australopithecines" (Johanson and White, 1979:328). Johanson and colleagues argue that the intermediate status of $A$. africanus metrics and morphology between $A$. afarensis and $A$. robustus + boisei prevents its inclusion as an ancestor of the Homo lineage. Here we examinine the australopithecine dental metric evidence and discuss whether dental metrics do indeed reinforce the taxonomic scheme of Johanson and colleagues.

It follows from Johanson and White's statements above that the inclusion of $A$. africanus in the ancestry of the Homo lineage must involve an evolutionary reversal in dental metric trends. The exact nature of such a dental metric reversal is expressed by Johanson and Edey (1981:285) in the following query: "Can molars start small, swell and then shrink again? . . I It is extremely unlikely." Thus, odontometrically, the reversal White et al. (1981) refer to would have been an increase in posterior tooth size from $A$. afarensis to $A$. africanus and subsequent decrease from $A$. africanus to $H$. habilis. Johanson and White (1979) maintain that the likelihood of such a reversal is low; they argue that this evidence, combined with data on cranial morphology, makes $A$. africanus an unlikely ancestor of the Homo clade.

The model of hominid evolution advanced by Johanson and White predicts, therefore, that in a continuous phylogenetic sequence of fossils from 4 through 1 mya intermediate samples will have cheek teeth that approximate the size of those of $H$. habilis or $A$. afarensis and not be larger. This hypothesis asserts stasis in dental metrics and in some morphological features in the lineage lead- ing to Homo, and is therefore referred to subsequently as the stasis hypothesis.

Alternatively, the placement of $A$. africanus in the ancestry of the Homo lineage must be labeled a reversal hypothesis in that it predicts that such intermediate samples will have cheek teeth that approximate the size of $A$. africanus dentitions and not be smaller.

Figure 1a [after White et al. (1981)] depicts the distribution of hominid fossils in Africa. As is illustrated, recent advances and persistent effort have yielded an adequate fossil record from which to begin interpretation (Bishop and Miller, 1972; Partridge, 1973; Butzer, 1974; Vrba, 1975; Coppens et al., 1976; Aronson et al., 1977; Brock et al., 1977; White and Harris, 1977; McFadden et al., 1979). Note that "gracile" fossils (A. afarensis) are found at Omo around 3 mya and then again (H. habilis) at less than 2 mya; it appears that there is a gap in the "gracile" fossil record from 3 to 2 mya. However, although little fossil evidence is known in East Africa for this 800,000 year period, the gap at Omo depicted in Figure 1a does not exist. Rather, as illustrated in Figure 1b, a continuous, though sparse, fossil record is found at Omo (Arambourg and Coppens, 1967; Arambourg et al., 1967, 1969; Heinzelin et al., 1970; Coppens, 1973; Howell et al., 1974; Howell and Coppens, 1976) from about 3 mya to less than 1 mya (Coppens, 1972, 1974, 1975; Brown and Nash, 1976; Brown and Shuey, 1976). Because Omo constitutes the only continuous hominid fossil record from $A$. afarensis through $H$. habilis, it offers a unique opportunity to test hypotheses of hominid phylogeny. We propose to use the Omo fossils to test the two hypotheses (reversal and stasis) outlined above by testing the two predictions that follow from these hypotheses. The stasis hypothesis predicts that intermediate (i.e., 3-2 mya) fossils at Omo will not have significantly larger cheek teeth than either A. afarensis or Homo, whereas the reversal hypothesis expects Omo dental metrics to resemble $A$. africanus and not be significantly smaller.

\section{MATERIALS AND METHODS Why use dental metrics?}

Beyond addressing the claim made by Johanson and colleagues that dental metrics reinforce their phylogenetic reconstruction, an odontometric analysis of Plio-Pleistocene hominids is of general use and can serve as the basis for further analysis. Although con- 

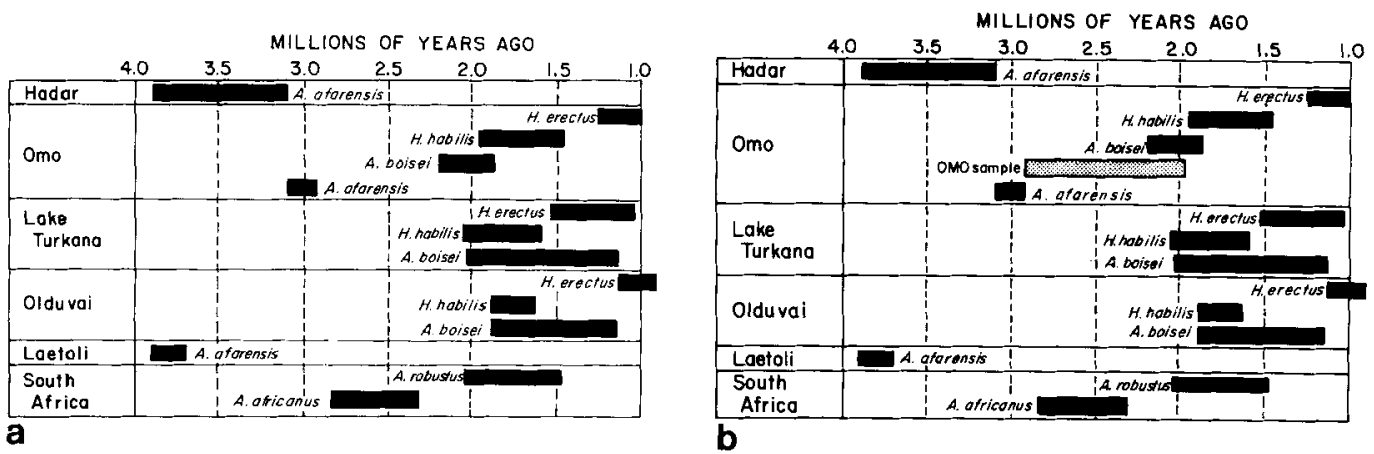

Fig. 1. a, Chronological and geographic placing of key early hominid localities and taxa. Redrawn from White et al. (1981), with permission. b, Chronological placement of key early hominid localities and taxa with the Omo sequence fully represented. The stippled bar repre sents gracile specimens found at Omo from $\sim 3-2$ mya.

clusions regarding phylogenetic relationships cannot be reached on the basis of tooth size alone, dental metrics are especially important when considering the early hominids because many of the morphological features distinguishing among the australopithecine taxa are intimately associated with variation in tooth size. For example, relatively large teeth imply great chewing forces and a suite of cranial features associated with such forces.

Because dental morphology is thought to be under relatively tight genetic control, evolutionarily conservative, and therefore highly diagnostic, attention often has focused on hominid cusp patterns. However, in hominids the cusps are worn away soon after eruption, leaving the occlusal area featureless and relatively flat (Brace, 1977). Since hominids all have similar enamel thicknesses (Jolly, 1970; Molnar and Gantt, 1977; Kay, 1981; Gantt, 1983), it is overall size that is the most important factor in determining how effectively and for how long a cheek tooth retains its grinding function. Size, therefore, is a major component of the hominid masticatory adaptation and an important feature to be considered in phylogenetic analysis.

Furthermore, a metric analysis of the Omo material is particularly appropriate because of the nature of the fossil record found there. The incomplete preservation of most of the Omo material has left very few nondental remains but a relatively abundant number of teeth available for analysis. Many of these teeth are worn flat, leaving fewer specimens for morphological assessment than for metric considerations.

\section{Body size and tooth size}

Raw measures of tooth size, however, are potentially misleading in animals that may be of different body weights. Recently, McHenry $(1983,1984)$ stated that it is not the "robust" species of australopithecines alone that are megadont but that the entire genus is characterized by this state. Instead of analyzing simple dental areas, McHenry's study utilized a ratio of dental area to estimated body size to compensate for possible differences in body mass. He concluded that variation in body size accounts for the differences in tooth size between $A$. africanus and $A$. afarensis. However, in his most recent investigation, McHenry (1985) found no difference in body size between $A$. afarensis, $A$. africanus, and $H$. habilis. This latest analysis revealed that megadontia is greatest in $A$. africanus, less in $A$. afarensis, and least in H. habilis. Since McHenry's (1985) findings on body weight are reiterated by other studies (Tobias, 1980; Steudel, 1980; Reed and Falk, 1977), we treat these three species as having indistinguishable body masses and consider tooth size without adjustment for body weight.

\section{Samples}

This study utilizes buccolingual dimensions from both maxillary and mandibular postcanine dentitions (too few anterior teeth are preserved at $\mathrm{Omo}$ for analysis). Analyses of dental metrics must consider the effects of dental wear on tooth size; the effect of wear on mesiodistal measures has been a topic of contention already in the $A$. africanus/A. afarensis debate (Tobias, 1980; White et al., 1981). Buccolingual diameters, however, are 
unaffected by approximal (also referred to as interproximal) wear (Brace, 1967a; Tobias, 1978). The buccolingual dimension, additionally, varies more between taxa (Blumenberg and Lloyd, 1983) and is therefore more diagnostic.

All measurements were made by a single observer (M.H. Wolpoff) on the original specimens. Teeth that could not be accurately measured and specimens of highly questionable taxonomic affinity were excluded from this analysis. When antimeres were present in an individual, an average of the two measurements was used. This method differs from that of Johanson and colleagues (Johanson and White, 1979; Johanson, 1980; White et al., 1981), who use only the right side when two measurements are available. Averaging helps to ameliorate the effects of measurement error and unrecognized postmortem alteration of tooth size and thereby reduces that portion of the samples' variances resulting from environmental influences. In addition, this method helps to compensate for undetected anomalies and fluctuating asymmetry. We believe that this technique increases the likelihood of recognizing biological differences between populations and makes the best use of small sample sizes.

Following Johanson (1980; see also Johanson and White, 1979), we divided our data into samples representing $A$. afarensis, $A$. africanus, $A$. robustus, $A$. boisei, and a fifth group that, again following Johanson (1980), consisted of both $H$. habilis and $H$. erectus specimens. An additional sample, not considered by Johanson and White (1979) or Johanson (1980), consisted of fossils from the middle layers $(\mathrm{C}-\mathrm{G})$ of Omo, Ethiopia.

The Laetoli/Hadar sample $(\mathrm{L} / \mathrm{H})$ contained all hominid specimens from Laetoli, Tanza- nia, and Hadar, Ethiopia, considered to be $A$. afarensis. The South African gracile sample (SAG) included the specimens attributed to A. africanus from Taung, Makapansgat, and Sterkfontein Member 4. Kromdraai and the Swartkrans non-Homo specimens constituted the South African robust (A. robustus) sample (SAR). A. boisei, the East African robust sample (EAR), consisted of the robust specimens from Olduvai beds I and II, East Turkana Lower and Upper Members, Natron, and Chesowanja. Gracile specimens from beds I and II at Olduvai and the East Turkana Lower and Upper Members formed the East African Homo sample (EAH).

The Omo sample consisted of all non- $A$. boise $i$ specimens from levels $\mathrm{C}-\mathrm{G}$ dated from approximately 3-2 mya (Coppens, 1972, 1974, 1975; Brown and Nash, 1976; Brown and Shuey, 1976). Hereafter, these specimens (non-A. boisei material from Omo levels $\mathrm{C}-$ G) will be referred to as the OMO sample (OMO) and will serve as a test for the predictions of the stasis and reversal hypotheses. The "gracile" specimens that constitute the OMO sample were distinguished from $A$. boisei specimens at Omo on the basis of dental morphology but are clearly distinct in size as well. As seen in Figures 2 and 3, the OMO and East African A. boisei samples display little overlap in tooth size. Space restrictions do not permit an additional figure; however, a similar lack of overlap in dental metrics occurs at Omo in "gracile" and A. boisei material, although the sample sizes are very small. Figures 2 and 3 also show that the various dental metrics of the OMO sample have standard deviations comparable to those of the other hominid samples, reinforcing the argument that this sample is not a mixture of specimens from smaller and larger species.

APPENDIX. Composition of OMO sample

\begin{tabular}{lllll}
\hline Level C & Level D & Level E & Level F & Level G \\
\hline L45-2 & L9-12 & L26-1 & L28-30 & L7-279 \\
L51-1 & L50-2 & L338X-34 & L28-31 & L427-7 \\
L51-2 & L296-1 & L338X-40 & L28-58 & L628-4 \\
L51-3 & L824-5 & L398-630 & L28-125 & L628-6 \\
L51-4 & & $57.4-41$ & L238-35 & L628-9 \\
L51-79 & $177-4525$ & L398-573 & L628-10 \\
L51-80 & & L398-1699 & L628-31 \\
L55-33 & & L398-2608 & L628-67 \\
L62-17 & & P933-1 & L894-1 \\
18S-31 & & $33-62$ & SH1.1-17 \\
18S-32 & & $33-506$ & $29.1-43$ \\
18S-33 & & $33-508$ & $47-1500$ \\
18S-34 & & $33-3282$ & $75-14$ \\
18S-37 & & $33-5496$ & $751-1255$ \\
18S-38 & & $76-13$ & 75 - 15 \\
18S-40 & & & 75 S-16 \\
18S-1799 & & & $195-1630$ \\
\hline
\end{tabular}




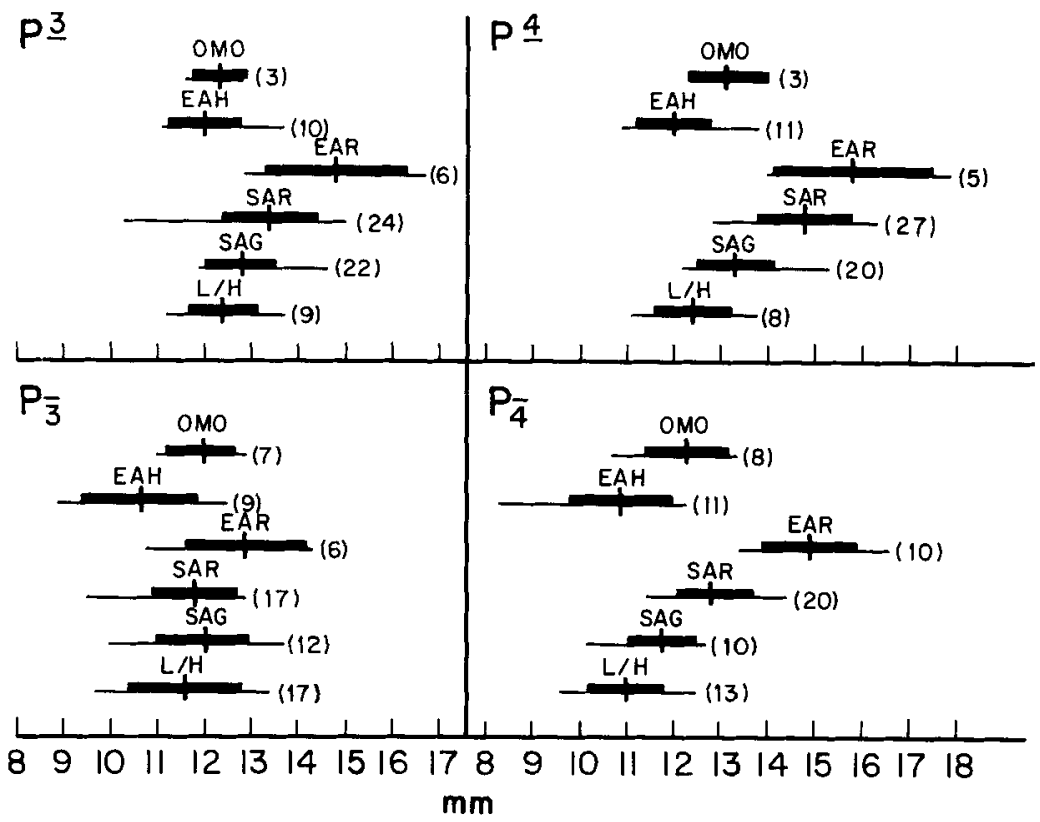

Fig. 2. Buccolingual premolar crown dimensions for Plio-Pleistocene hominids. See text for explanation of sample groups. Vertical lines are means, narrow horizontal lines ranges, and heavy horizontal lines SDs. Sample sizes are presented in parentheses after each bar.

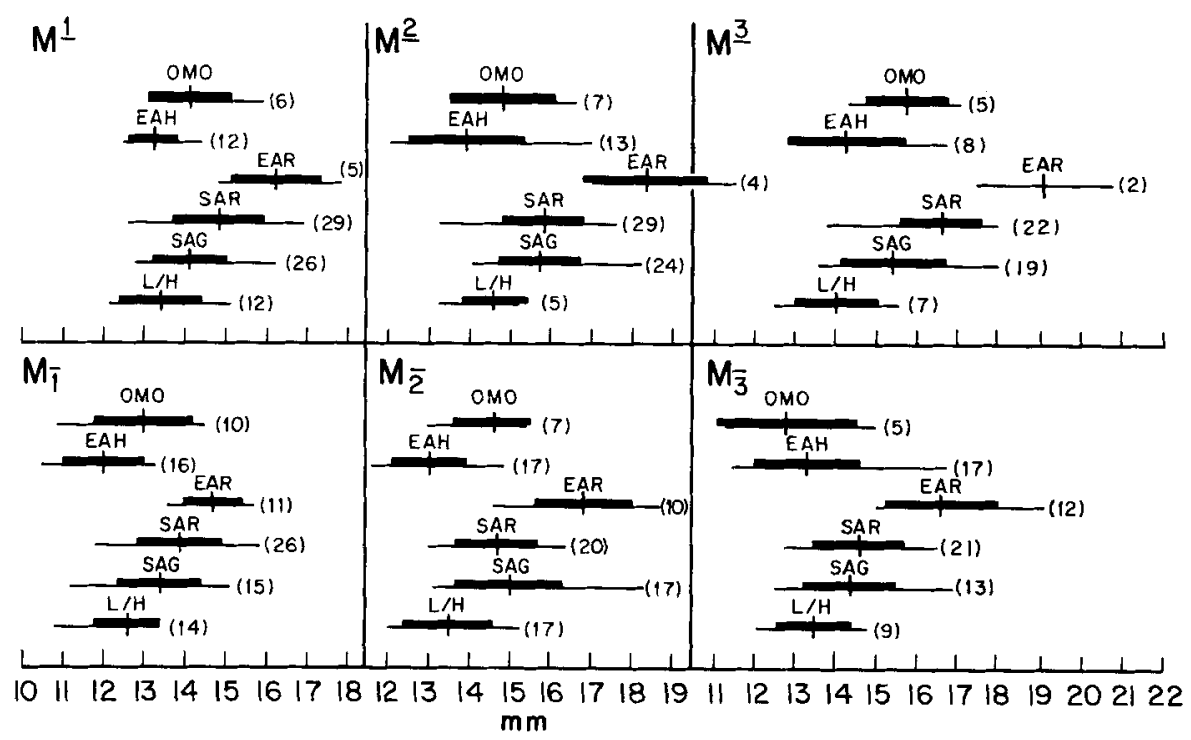

Fig. 3. Buccolingual molar crown dimensions for Plio-Pleistocene hominids. See text for explanation of sample groups. Vertical lines are means, narrow horizontal lines ranges, and heavy horizontal lines SDs. Sample sizes are presented in parentheses after each bar.

\section{Statistical analysis}

The stasis hypothesis predicts that OMO will not be significantly larger than either A. afarensis or Homo, whereas the reversal hypothesis expects OMO dental metrics to resemble $A$. africanus and not be significantly smaller. To test these predictions, the similarity of the four samples to one another was evaluated for each tooth using an anal. ysis of variance (ANOVA); the level of significance was set at $P \leqslant 0.05$. When the ANOVA revealed a significant difference among the four sample means, pairwise contrasts between OMO and each of the other 
three samples were conducted. Such pairwise comparisons are not independent, and simultaneous inference of the results of these tests must take this into consideration. The Bonferroni technique (Miller, 1966) deals effectively with this difficulty; the significance for the set of contrasts is kept at $\mathrm{P} \leqslant 0.05$, whereas that of each contrast is considerably stricter.

An additional, although separate, consideration is the similarity of OMO to the two other australopithecine samples: EAR and SAR. An ANOVA of these three samples was conducted for each tooth and, when significant, pairwise contrasts were obtained, again utilizing the Bonferroni technique to assess the results.

\section{RESULTS}

Sample statistics are presented in Table 1 and illustrated in Figure 2 (premolars) and Figure 3 (molars). Sample means and SDs for each group are very similar to those figured by Johanson and White (1979), despite the fact that the teeth were measured by different observers and are in all likelihood made up of slightly different samples. Table 2 gives the difference in sample means and the significance level for each pairwise contrast.

The ANOVA of the four sample means (OMO, L/H, EAH, SAG) for each of the ten postcanine teeth revealed only one nonsignificant set: $\mathrm{P}^{3}$. Of the nine remaining teeth, OMO is significantly $(\mathrm{P} \leqslant 0.05$ ) larger than the $\mathrm{L} / \mathrm{H}$ sample for $\mathrm{M}^{3}, \mathrm{P}_{4}$, and $\mathrm{M}_{2}$ and larger

TABLE 1. Sample statistics for buccolingual dimensions

\begin{tabular}{|c|c|c|c|c|c|c|c|}
\hline \multirow{2}{*}{\multicolumn{2}{|c|}{ Tooth }} & \multicolumn{6}{|c|}{ Samples } \\
\hline & & OMO & $\mathrm{L} / \mathrm{H}$ & $\mathrm{EAH}$ & SAG & SAR & EAR \\
\hline \multicolumn{8}{|c|}{ Maxilla } \\
\hline \multirow[t]{4}{*}{ P3 } & $\bar{X}$ & 12.30 & 12.43 & 12.04 & 12.77 & 13.4 & 14.79 \\
\hline & $\mathrm{SD}$ & 0.625 & 0.685 & 0.787 & 0.766 & 1.027 & 1.460 \\
\hline & Range & $11.60-12.80$ & $11.20-13.70$ & $11.05-13.65$ & $11.85-14.60$ & $10.30-15.02$ & $12.9-16.77$ \\
\hline & $\underline{\mathrm{n}}$ & 3 & 9 & 10 & 22 & 24 & 6 \\
\hline \multirow[t]{4}{*}{$\mathbf{P 4}$} & $\overline{\mathrm{X}}$ & 13.12 & 12.38 & 12.03 & 13.29 & 14.83 & 15.78 \\
\hline & $\mathrm{SD}$ & 0.931 & 0.805 & 0.764 & 0.845 & 0.950 & 1.721 \\
\hline & Range & $12.25-14.10$ & $11.10-13.80$ & $10.90-13.80$ & $12.25-15.30$ & $12.85-16.3$ & $14.0-17.85$ \\
\hline & $\underline{n}$ & 3 & 8 & 11 & 20 & 27 & 5 \\
\hline \multirow[t]{4}{*}{ M1 } & $\overline{\mathrm{X}}$ & 14.13 & 13.36 & 13.18 & 14.10 & 14.81 & 16.24 \\
\hline & $\mathrm{SD}$ & 1.007 & 0.980 & 0.637 & 0.855 & 1.117 & 1.085 \\
\hline & Range & $13.20-15.90$ & $12.10-15.10$ & $12.45-14.40$ & $12.75-16.20$ & $12.6-17.90$ & $14.75-17.8$ \\
\hline & $\underline{\mathrm{n}}$ & 6 & 12 & 12 & 26 & 29 & 5 \\
\hline \multirow[t]{4}{*}{ M2 } & $\overline{\mathrm{X}}$ & 14.83 & 14.55 & 13.88 & 15.74 & 15.80 & 18.28 \\
\hline & $\mathrm{SD}$ & 1.272 & 0.771 & 1.439 & 1.077 & 1.033 & 1.532 \\
\hline & Range & $13.50-16.60$ & $13.25-15.20$ & $12.00-17.00$ & $14.10-18.20$ & $13.2-17.6$ & $17.0-20.45$ \\
\hline & $\mathrm{n}$ & 7 & 5 & 13 & 24 & 29 & 4 \\
\hline \multirow[t]{4}{*}{ M3 } & $\overline{\mathrm{X}}$ & 15.72 & 14.05 & 14.24 & 15.40 & 16.56 & 19.13 \\
\hline & $\mathrm{SD}$ & 1.040 & 0.968 & 1.451 & 1.287 & 1.012 & 2.369 \\
\hline & Range & $14.30-17.00$ & $12.50-15.50$ & $12.80-16.65$ & $13.60-19.05$ & $13.8-18.0$ & $17.45-20.80$ \\
\hline & $\mathrm{n}$ & 5 & 7 & 8 & 19 & 22 & 2 \\
\hline \multicolumn{8}{|c|}{ Mandible } \\
\hline \multirow[t]{4}{*}{ P3 } & $\bar{X}$ & 11.97 & 11.58 & 10.66 & 12.00 & 11.77 & 12.91 \\
\hline & SD & 0.702 & 1.190 & 1.178 & 1.021 & 0.925 & 1.311 \\
\hline & Range & $11.00-12.90$ & $9.70-13.40$ & $8.90-12.50$ & $10.05-13.65$ & $9.45-12.9$ & $10.8-14.3$ \\
\hline & $\underline{n}$ & 7 & 17 & 9 & 12 & 17 & 6 \\
\hline \multirow[t]{4}{*}{$\mathrm{P} 4$} & $\bar{X}$ & 12.33 & 11.04 & 10.92 & 11.84 & 12.94 & 14.92 \\
\hline & SD & 0.896 & 0.827 & 1.109 & 0.713 & 0.820 & 1.031 \\
\hline & Range & $10.65-13.30$ & $9.60-12.45$ & $8.30-12.30$ & $10.20-12.65$ & $11.45-14.35$ & $13.4-16.55$ \\
\hline & $\underline{\mathbf{n}}$ & 8 & 13 & 11 & 10 & 20 & 10 \\
\hline \multirow[t]{4}{*}{ M1 } & $\overline{\mathrm{X}}$ & 12.95 & 12.57 & 11.96 & 13.36 & 13.90 & 14.73 \\
\hline & $\mathrm{SD}$ & 1.207 & 0.826 & 0.971 & 1.009 & 1.020 & 0.748 \\
\hline & Range & $10.90-14.50$ & $10.80-13.40$ & $10.50-13.30$ & $11.20-15.05$ & $11.8-15.8$ & $13.6-15.7$ \\
\hline & $\underline{n}$ & 10 & 14 & 16 & 15 & 26 & 11 \\
\hline \multirow[t]{4}{*}{ M2 } & $\overline{\mathrm{X}}$ & 14.56 & 13.49 & 13.02 & 14.98 & 14.71 & 16.83 \\
\hline & SD & 0.888 & 1.068 & 0.928 & 1.327 & 1.005 & 1.162 \\
\hline & Range & $13.00-15.38$ & $12.00-15.20$ & $11.60-14.80$ & $13.15-18.30$ & $12.95-16.38$ & $14.6-18.65$ \\
\hline & $\underline{\mathbf{n}}$ & 7 & 17 & 17 & 17 & 20 & 10 \\
\hline \multirow[t]{4}{*}{ M3 } & $\bar{X}$ & 12.82 & 13.50 & 13.28 & 14.37 & 14.57 & 16.56 \\
\hline & SD & 1.672 & 0.919 & 1.288 & 1.077 & 1.054 & 1.361 \\
\hline & Range & $11.30-15.00$ & $12.05-14.75$ & $11.50-16.65$ & $12.60-16.93$ & $12.8-16.5$ & $15.0-19.22$ \\
\hline & $\pi$ & 5 & 9 & 17 & 13 & 21 & 12 \\
\hline
\end{tabular}


TABLE 2. Difference in sample means and significance level ${ }^{1}$ for pairwise comparisons of OMO

\begin{tabular}{|c|c|c|c|c|c|c|}
\hline \multirow[b]{3}{*}{ Tooth } & \multicolumn{6}{|c|}{ Comparative samples } \\
\hline & \multicolumn{2}{|c|}{ OMO vs. L/H } & \multicolumn{2}{|c|}{ OMO vs. EAH } & \multicolumn{2}{|c|}{ OMO vs. SAG } \\
\hline & $\begin{array}{l}\text { Difference } \\
\text { in means } \\
\end{array}$ & $\mathrm{P}$ & $\begin{array}{l}\text { Difference } \\
\text { in means }{ }^{2}\end{array}$ & $\mathrm{P}$ & $\begin{array}{l}\text { Difference } \\
\text { in means }\end{array}$ & $\mathbf{P}$ \\
\hline $\mathrm{P}^{4}$ & 0.74 & NS & 1.09 & 0.073 & -0.17 & NS \\
\hline $\mathbf{M}^{1}$ & 0.77 & NS & 0.95 & 0.047 & 0.03 & NS \\
\hline $\mathbf{M}^{2}$ & 0.28 & NS & 0.95 & NS & -0.91 & NS \\
\hline $\mathbf{M}^{3}$ & 1.67 & 0.043 & 1.48 & 0.068 & 0.32 & NS \\
\hline$P_{3}$ & 0.39 & NS & 1.31 & 0.032 & -0.03 & $\mathrm{NS}$ \\
\hline $\mathrm{P}_{4}$ & 1.29 & 0.004 & 1.41 & 0.003 & 0.49 & NS \\
\hline $\mathrm{M}_{1}$ & 0.38 & NS & 0.99 & 0.025 & -0.41 & NS \\
\hline $\mathrm{M}_{2}$ & 1.07 & 0.050 & 1.54 & 0.004 & -0.42 & NS \\
\hline $\mathbf{M}_{3}$ & -0.68 & NS & -0.46 & NS & -1.55 & 0.029 \\
\hline
\end{tabular}

${ }^{1}$ Adjusted using Bonferroni technique.

${ }^{2} \mathrm{~A}$ positive value indicates that OMO sample mean is greater than that of comparative sample.

than the EAH sample for $\mathrm{M}^{1}, \mathrm{P}_{3}, \mathrm{P}_{4}, \mathrm{M}_{1}$, and $\mathrm{M}_{2}$. In addition, OMO is larger than EAH at $\mathrm{P} \leqslant 0.10$ for $\mathrm{P}^{4}$ and $\mathrm{M}^{3}$. In contrast, $\mathrm{OMO}$ is significantly smaller than SAG for only a single tooth: $\mathrm{M}_{3}$. All other pairwise contrasts are nonsignificant at $\mathrm{P}>0.10$.

In sum, on the basis of this statistical analysis, the dental metrics of the OMO sample are not very similar to those of the EAH sample and are somewhat more similar to those of the $\mathrm{L} / \mathrm{H}$ sample. However, the OMO sample is nearly identical in tooth size to the SAG sample; only one tooth $\left(\mathrm{M}_{3}\right)$ is significantly different (see Figs. 2 and 3).

Furthermore, the OMO sample does not bear much odontometric resemblance to any other australopithecine sample. Table 3 presents the results of an ANOVA and pairwise contrasts of the OMO, South African robust (SAR), and East African robust (EAR) samples. Only one of the ANOVA analyses is not significant: $\mathrm{P}_{3}$. The OMO and EAR samples are significantly different for every other tooth. OMO is smaller than SAR in four cases at $P \leqslant 0.05$ and in one case at $P \leqslant 0.10$, a degree of similarity comparable to that of OMO and EAH.

Table 4 summarizes the statistically significant differences between OMO and the other five samples. Clearly, of all possible taxa that the OMO sample might be expected to resemble, the greatest postcanine odontometric affinity is with $A$. africanus.

\section{DISCUSSION}

The stasis hypothesis predicts that postcanine dentitions in the $A$. afarensis-Homo lineage will remain very similar in size at every evolutionary step. The continuous sequence of fossils at Omo offers a unique op-
TABLE 3. Difference in sample means and significance level ${ }^{1}$ for pairwise comparisons of $O M O$

\begin{tabular}{|c|c|c|c|c|}
\hline \multirow[b]{3}{*}{ Tooth } & \multicolumn{4}{|c|}{ Comparative samples } \\
\hline & \multicolumn{2}{|c|}{ OMO vs. SAR } & \multicolumn{2}{|c|}{ OMO vs. EAR } \\
\hline & $\begin{array}{l}\text { Difference } \\
\text { in means } \\
\end{array}$ & $\mathrm{P}$ & $\begin{array}{l}\text { Difference } \\
\text { in means }\end{array}$ & $\mathrm{P}$ \\
\hline$P^{3}$ & -1.10 & NS & -2.49 & 0.003 \\
\hline$P^{4}$ & -1.71 & 0.014 & -2.66 & 0.002 \\
\hline $\mathbf{M}^{1}$ & -0.67 & NS & -2.12 & 0.003 \\
\hline $\mathbf{M}^{2}$ & -0.97 & 0.048 & -3.45 & 0.0000 \\
\hline $\mathbf{M}^{3}$ & -0.84 & NS & -3.41 & 0.001 \\
\hline $\mathrm{P}_{4}$ & -0.61 & 0.100 & -2.59 & 0.0000 \\
\hline $\mathbf{M}_{1}$ & -0.95 & 0.015 & -1.78 & 0.0002 \\
\hline $\mathbf{M}_{2}$ & -0.15 & NS & -2.27 & 0.0001 \\
\hline $\mathbf{M}_{3}^{2}$ & -1.75 & 0.008 & -3.74 & 0.0000 \\
\hline
\end{tabular}

${ }^{1}$ Adjusted using Bonferroni technique.

${ }^{2} \mathrm{~A}$ positive value indicates that $O M O$ mean is greater than that of comparative sample.

TABLE 4. Summary of statistically significant differences between the OMO sample and $\mathrm{A}$. afarensis $(L / H)$, A. africanus $(S A G)$, A. robustus $(S A R)$, A. boisei $(E A R)$, and Homo (EAH).

OMO vs. $\mathrm{L} / \mathrm{H} \quad \mathrm{M}^{3}, \mathrm{P}_{4}, \mathrm{M}_{2}$

OMO vs. EAH $\quad \mathrm{P}^{4}, \mathrm{M}^{1}, \mathrm{M}^{3}, \mathrm{P}_{3}, \mathrm{P}_{4}, \mathrm{M}_{1}, \mathrm{M}_{2}$

OMO vs. SAG $\quad \mathrm{M}_{3}$

OMO vs. SAR $\quad \mathrm{P}^{4}, \mathrm{M}^{2}, \mathrm{P}_{4}, \mathrm{M}_{1}, \mathrm{M}$

OMO vs. EAR $\quad \mathrm{P}^{3}, \mathrm{P}^{4}, \mathrm{M}^{1}, \mathrm{M}^{2}, \mathrm{M}^{3}, \mathrm{P}_{4}, \mathrm{M}_{1}, \mathrm{M}_{2}, \mathrm{M}_{3}$

portunity to test this hypothesis in that the early specimens at this site have been designated $A$. afarensis (White et al., 1981) and the later ones $H$. habilis (Howell and Coppens, 1976; White et al., 1981). The OMO sample, chronologically intermediate with respect to $A$. afarensis and Homo specimens, displays dental metrics most similar to South African $A$. africanus. This finding is contrary to the expectation of the stasis hypothesis (see Fig. 4a), which predicts that if such an intermediate sample is indeed in the $A$. afar- 
a. STASIS

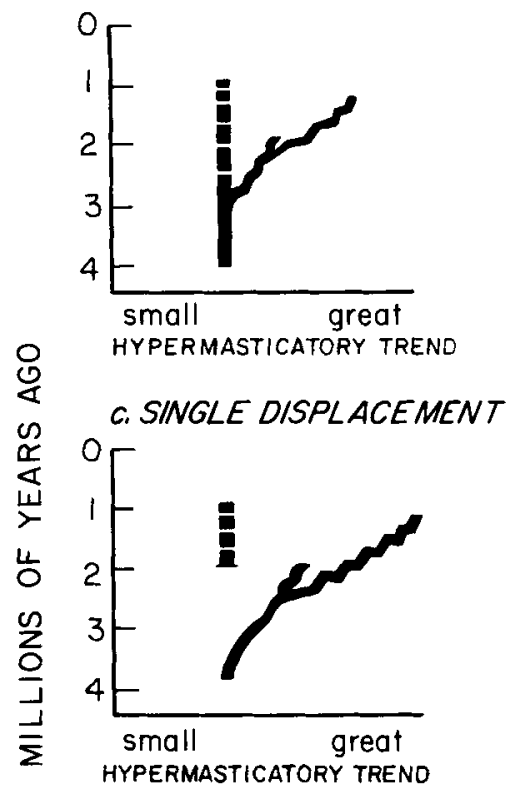

b. PARALLELISM

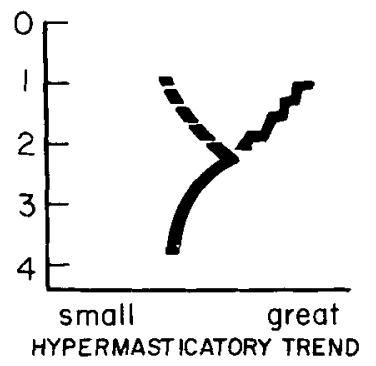

d. DOUBLE DISPLACEMENT

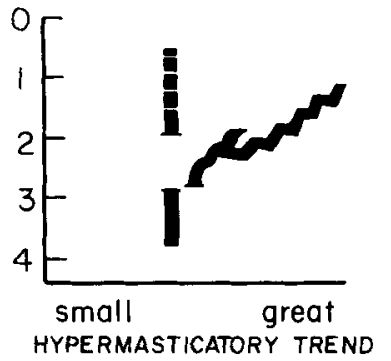

e. REVERSAL

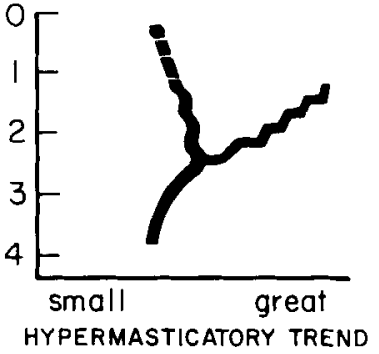

Fig. 4. Five possible evolutionary scenarios at Omo. Vertical axis represents time; horizontal axis represents the relative expression of the hypermasticatory trend, an adaptation characterized by the hypertrophy of a morphological complex, including the posterior dentition, associated with heavy mastication (see text for further explanation). Each taxon is represented by a different line style; the evolution of one taxon into another is depicted as a blending of the two appropriate styles. a, The stasis hypothesis. No change in the hypermasticatory trend is evident in the Homo clade from 4 to 1 mya. $A$. africanus branches off the Homo clade early. b, The parallelism hypothesis. Although the Homo clade undergoes hypermasticatory evolution, the Omo sample from 3-2 mya is not $A$. africanus; the similarities between $\mathrm{OMO}$ and $A$. africanus are due to parallelism. c,

ensis-Homo lineage, it will exhibit dental metrics most similar to $A$. afarensis or Homo or both.

Although the dental metric evidence from Omo does not support a picture of hominid evolution typified by unchanging posterior tooth size from $A$. afarensis through the first

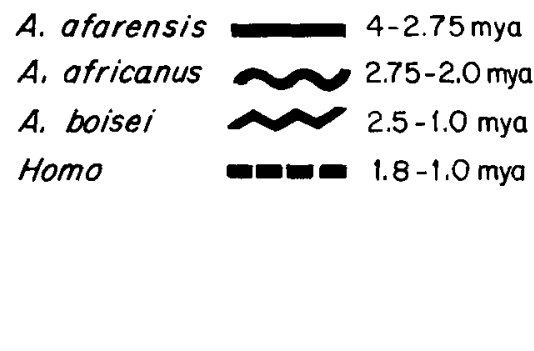

The single displacement hypothesis. Consistent with the stasis hypothesis, this hypothesis maintains that for the 800,000 year fossil gap the Homo clade was evolving somewhere other than at Omo, returning at about 2 mya to replace $A$. africanus. There are no known fossils from the 800,000 year gap representing a separately evolving Homo lineage. d, The double displacement hypothesis. The Homo clade was displaced from Omo for the 800,000 year gap and returns to displace $A$. africanus. e, The reversal hypothesis. The fossils at Omo represent an evolving lineage that underwent hypermasticatory evolution; this trend reversed with the evolution of the Homo clade but continued in the australopithecine clade. This hypothesis does not rely on undiscovered fossil species or specimens but does require a change in selection pressure and a reversal of dental metric evolution.

Homo species, and thus is contrary to the stasis hypothesis, neither does it necessarily indicate that $A$. africanus is indeed ancestral to $H$. habilis. Rather, there are four possible hypotheses that explain the metric resemblance between the OMO sample and the $A$. africanus sample. 


\section{The parallelism hypothesis}

Although the OMO sample dental metrics are similar to those of the A. africanus sample, the taxon represented by OMO may have come to resemble $A$. africanus in dental metrics but is not conspecific with $A$. africanus. In other words, the OMO sample represents a taxon in the A. afarensis-Homo lineage that is not the same species represented by the SAG sample despite the metric resemblance between the two (see Fig. 4b).

\section{The displacement hypotheses}

It is possible that the species found at the intermediate levels $(\mathrm{C}-\mathrm{G})$ at Omo is $A$. africanus but that it is not ancestral to later Homo species. Instead, it might be hypothesized that the $A$. africanus population sampled at Omo was displaced by members of the Homo clade. There are two different displacement hypotheses.

Single displacement: The population of $A$. afarensis represented by the specimens found at the earliest levels at Omo may have evolved in situ into $A$. africanus, as represented by our OMO sample, but this taxon was then later displaced by Homo, the fossils found in Omo's most recent levels (see Fig. $4 \mathrm{c}$ ).

Double displacement: Another possibility is that $A$. afarensis as represented at Omo may have been ancestral to later Homo populations but that some $A$. africanus population displaced the $A$. afarensis-Homo lineage for the time period from which our sample is taken. Homo subsequently returned, displacing $A$. africanus, having evolved into a recognizably Homo form elsewhere (see Fig. 4d).

In both of these scenarios the Omo population in our sample represents $A$. africanus, the first hypothesis necessitating a displacement of $\boldsymbol{A}$. africanus by Homo, the second requiring an initial displacement of $A$. afarensis by $A$. africanus and a later displacement of $A$. africanus by $H$. habilis.

\section{The reversal hypothesis}

The dental sample at Omo may represent a single evolving lineage that underwent an evolutionary increase and a subsequent decrease in cheek teeth dimensions. In other words, $A$. afarensis evolved into $A$. africanus, which in turn evolved into $H$. habilis (see Fig. 4e).

\section{Which one?}

These, then, are four hypotheses to explain the OMO sample's resemblance to $A$. afri- canus. An examination of dental metrics alone cannot refute the parallelism hypothesis. However, there is no reason to hypothesize that two fossil samples from the same time period with the same dental metrics are of two different species unless their morphologies are so different as to preclude their representing the same species (Mayr, 1966:338; Le Gros Clark, 1969). Workers who have examined the Omo fossils (Howell, 1969, 1975; Howell and Coppens, 1973, 1976; Coppens, 1980) have noted the morphological similarities between the Omo material from levels $\mathrm{C}-\mathrm{G}$ and $A$. africanus. Given these details and the metrics of the Omo group, it is unnecessarily convoluted to hypothesize that two samples as metrically and morphologically similar as that representing South African $A$. africanus and OMO have developed their similarities in parallel rather than that the two samples are of the same species. This does not disprove parallelism; rather, with currently available fossil evidence, it simply appears less likely than alternative hypotheses. Furthermore, it should be noted that, if one argues that a dental metric reversal is so unlikely as to remove $A$. africanus from the A. afarensis-Homo lineage, then the same argument must be applied to exclude the OMO sample, independent of its specific affinity to $A$. africanus. That is, the fossils from the middle layers of Omo could not be ancestral to later Homo species under the same logic that excludes SAG as an ancestor of Homo.

Three hypotheses remain. The double displacement hypothesis requires first that a population of $A$. africanus-like individuals displaced a population of $\boldsymbol{A}$. afarensis-like australopithecines and subsequently that a population of habilines, having evolved from an $A$. afarensis population elsewhere, returned, displacing the australopithecines. It also necessitates leaving an 800,000 year gap in the fossil record, since to sustain it one must accept the evolution of a separate $A$. a farensis-Homo lineage elsewhere, a lineage that has not yet been discovered. There is no evidence to support a displacement at Omo between levels containing what might be called $A$. afarensis and what may be $A$. africanus (Howell and Coppens, 1976). Although noting a size increase in dentition between the levels dated greater than 3 mya (i.e., Usno and Shungura A and B) and later levels, Howell and Coppens (1976:523,524) state explicitly that there is no morphological rubicon. Instead, they describe specimens from 
the greater-than-3-mya levels as smaller, more primitive representatives of $A$. africanus. Whether these earlier specimens are called $A$. afarensis or not is beside the point; they are similar to the specimens from later levels, referred to $A$. africanus, and metrically and morphologically grade into them.

The transition between what might be called $A$. africanus and specimens provisionally assigned to $H$. habilis, however, is not clear. In level $\mathrm{G}$, some specimens are said to resemble $A$. africanus, others are said to be "comparable to" $H$. habilis, and still others are described simply as divergent from the morphology of the robust specimens. None of the "gracile" specimens is said to show unequivocal association with either $A$. africanus or $H$. habilis. At no point do Howell and Coppens note a sudden appearance of a specimen with $H$. habilis dental morphology. The lack of a clear morphological rubicon supports the reversal hypothesis.

If a displacement had occurred, one might expect a dramatic tooth size reduction at some point in the sequence, but sample sizes at Omo are too small to determine accurately whether such a change occurs. Given the evidence in the early levels of Omo, it seems warranted to judge the double displacement hypothesis as unlikely. However, the equivocal status of the later specimens prevents a definitive assessment of the single replacement hypothesis.

The reversal hypothesis requires that the cheek teeth first increased and then decreased in size. Evolutionary reduction of tooth size has been amply demonstrated in the fossil record for primates (Gingerich, 1976a,b, 1979; Gingerich and Schoeninger, 1977). Furthermore, this phenomenon is not limited to nonhuman primates; Brace (1979, 1980) has demonstrated both increase and subsequent decrease in dental dimensions in a hominid lineage. It is not unusual, therefore, to observe a reduction in tooth size during the evolution of a lineage; consequently the reversal hypothesis is viable.

The single displacement hypothesis and the reversal hypothesis, of the four outlined above, are the two most plausible hypotheses to explain hominid evolution at Omo. Both the parallelism and the double displacement hypotheses are unnecessarily convoluted given the present evidence.

\section{Reversal vs. stasis}

At Omo, there is a continuous series of fossils beginning with $A$. afarensis and end- ing with Homo. The intermediate hominid fossils exhibit dental metrics nearly identical to those of $A$. africanus. Should this series of hominids be considered a single lineage? If so, one must accept a number of reversals between $A$. africanus and $H$. habilis involving cheek tooth size and a suite of cranial and mandibular features (Corrucini and McHenry, 1980; Rak, 1983, 1985; White et al., 1981; Tobias, 1980, 1985; Kimbel et al., 1984; White, 1985; Olson, 1981, 1985). If not, alternatively we must accept three corollaries: a displacement, the coexistence of three hominid species, and an absence of fossils having dentitions resembling those of $A$. afarensis or $H$. habilis at Omo or anywhere else during the 800,000 year gap between $\mathrm{L} / \mathrm{H}$ and $\mathrm{EAH}$. Yet $A$. africanus-like dentitions have been discovered both in South Africa and at Omo in East Africa (contra Leakey, 1972, 1973; Campbell, 1978; White et al., 1981; Wood, 1978) dating to this period.

How different is the cranial morphology of A. africanus from that of $A$. afarensis/ $H$. $h a-$ bilis, and how many reversals are there if $A$. afarensis, A. africanus, and Homo are considered a single lineage? Johanson, White, Kimbel, and their colleagues document an impressive number of morphological similarities between $A$. afarensis and Homo, noting that these traits diverge in $A$. africanus. It is tempting to treat the differences between $A$. afarensis and $A$. africanus as a great number of independent differences, treating the similarities in the masticatory morphology of $A$. afarensis and Homo as a plethora of independent similarities. This kind of assessment ignores the fact that most of the differences between $A$. afarensis and $A$. africanus are part of a single functional complex [as White et al. (1981) stress] and therefore that the various features involved in this complex must have evolved together as a unit. $A$. africanus has relatively large cheek teeth, and relatively large cheek teeth imply great chewing forces. Associated with great chewing forces are a number of other morphological traits (Le Gros Clark, 1947, 1969; Broom and Robinson, 1952; Robinson, 1954, 1956, 1958, 1962, 1963, 1972; Brace, 1976b, 1973; Tobias, 1967, 1973; Jolly, 1970; Wolpoff, 1974, 1980; Howell, 1975; DuBrul, 1977; White, 1977; Clarke, 1979; Hylander, 1979; Johanson and White, 1979; Ward, 1979; Ward and Molnar, 1980; White et al., 1981; Kimbel et al., 1982, 1984; White and Johanson, 1982; Rak, 1983, 1985), among these thicker mandibular corpora; taller, more vertical ascend- 
ing rami; higher, straighter zygomatic process roots; greater malar robusticity; dishing of the face; anterior placement of the zygomae; retracted palate; expanded temporal fossa; presence of anterior pillars; and an anteriorly placed sagittal crest. We proposed (Hunt and Vitzthum, 1984) calling this suite of characters the hypermasticatory complex and the increase in the expression of this complex the hypermasticatory trend because this evolutionary pattern is characterized by the hypertrophy of a morphological complex, including the posterior dentition, associated with heavy mastication.

Rather than viewing early hominid evolution as a series of reversals (or, conversely, as a lack of them), it is more appropriate to view the evolution of the hominids as exemplified by two trends. The first trend is the consistent and continuing evolution of dental and gnathic adaptations for the consumption of hard-packaged and/or abrasive foodstuffs without the benefit of advanced food-processing technology. The australopithecine lin eage, beginning before $A$. afarensis and ending with $A$. boisei, represents this gradual hypermasticatory evolution. Somewhere along the australopithecine lineage a change in adaptation altered the selective forces on the dentition and face producing a second trend. Specifically, a change in diet or food processing reduced the forces applied to the dentition during mastication; therefore, the selective pressures to maintain large dentitions and the cranial and mandibular superstructures associated with large dentitions and great masticatory forces were lessened and these structures subsequently reduced. Individuals exhibiting this second trend constitute the base of the Homo lineage. The many morphological similarities between $A$. afarensis and Homo are not a group of independent data points but a very closely related complex of features that hypertrophied in response to a single evolutionary pressure-the selection for the ability to produce greater masticatory force-and reduced when selection for this ability decreased (see Fig. 5).

Neither the stasis nor the reversal hypothesis is incompatible with the arguments regarding trends in masticatory adaptations outlined above. The difference between the two hypotheses is simply when the Homo lineage branched off from the australopithecine lineage. If it was very early (i.e., $\sim 3.5$ mya; see Fig. 5), then the stasis model may properly describe hominid evolution in the
Pliocene. If it was late (i.e., $\sim 2.5$ mya), the reversal hypothesis is correct (see Fig. 5). We agree with many of the points elaborated by Kimbel (1984) and Kimbel et al. (1984), as well as some of the contra arguments presented by Tobias (1980); it is possible that speciation occurred during a time period intermediate between currently known $A$. afarensis and $A$. africanus samples. If this is the case, the stasis/reversal dichotomy will be shown to have been an artifact of the history of australopithecine discoveries.

\section{How different are A. afarensis, A. africanus, and $\mathrm{H}$. habilis?}

An unresolved issue in paleontological studies is the expected or acceptable level of metric variation, for any feature, within a fossil species. A number of workers have maintained that two species are represented in the $A$. afarensis sample (Coppens, 1981, 1983; Olson, 1981, 1985; Read, 1984; Senut and Tardieu, 1985; Zihlman, 1985). Tobias $(1980,1985)$ has pointed out that the specimens from Laetoli have dental metrics very similar to those of $A$. africanus, whereas the Hadar specimens are much smaller. Yet White and colleagues (Johanson and White, 1979; White et al., 1981; Kimbel et al., 1982, 1985; White, 1985) have defended A. afarensis as a single species, distinct from $A$. africanus, on the basis that "to find a statistically significant difference between several populations is only of minor interest to the tax-

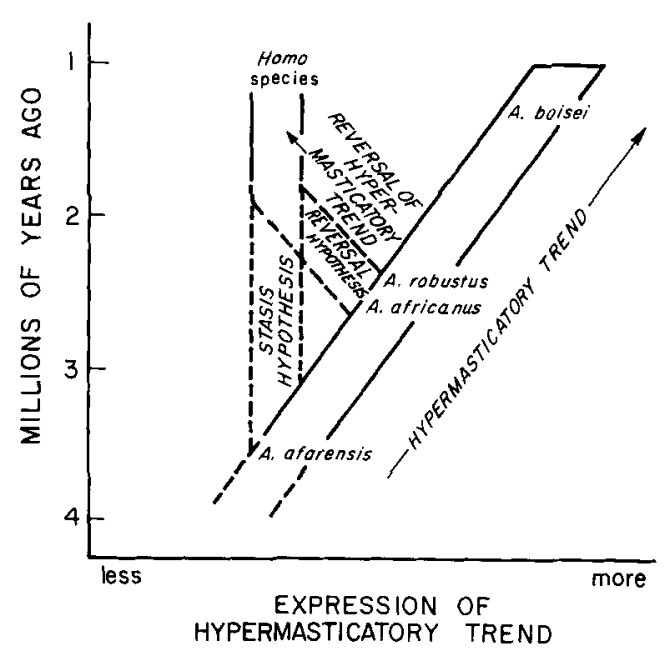

Fig. 5. Australopithecine phylogeny and the expres. sion of the hypermasticatory trend. The difference between the stasis hypothesis and the reversal hypothesis is the timing of the speciation process that produced the Homo lineage. 
onomist; he takes it for granted" (Mayr, 1969:187; quoted in White, 1985). We cannot present a more eloquent argument against unwarranted splitting. Just as dividing Laetoli and Hadar on the basis of small average differences in size and morphology appears unwarranted, so is concluding that $A$. africanus is too hypermasticatory to be an ancestor of the Homo lineage when there is considerable overlap of ranges of tooth size in the taxa of interest (see Figs. 2 and 3) and a chronology that allows adequate time for the evolution of the hypermasticatory complex to have occurred.

Metric similarity aside, an additional and perhaps less resolved issue in phylogenetic reconstruction is the acceptable or expected level of morphological variation within a fossil species. Corrucini and McHenry (1980) noted the similarity of $A$. afarensis and $H$. habilis dental anatomy, while showing $A$. africanus to be less closely related to A. afarensis or $H$. habilis than to $A$. robustus. However, these findings do not bear directly on the material at Omo considered in our analysis. Corrucini and McHenry's study was conducted on $A$. africanus specimens from South Africa, thousands of miles from Omo. Geographical variation in dental size and morphology is to be expected among populations of $A$. africanus. Specifically, OMO is expected to vary in the direction of the earlier (A. afarensis) and later (H. habilis) specimens at Omo. In addition, the differences they observed between $A$. afarensis and $A$. africanus in dental morphology may be due to allometry. It is not clear whether occlusal morphology changes isometrically when there is selection for, and subsequently the evolution of, larger teeth. A, africanus dental morphology may be a scaled version of $A$. afarensis morphology. It should also be noted that only 10 (of 34) measures made by Corrucini and McHenry on the dentition are actually on surface topology; the others are cervical breadth, cervical length, occlusal length, diagonal length, and crown height. These metric variables are not only very interdependent (Butler, 1937, 1939, 1961, 1963; Dahlberg, 1945, 1950, 1951, 1963) but are simply expressions of dental size, not of dental morphology. Differences among these taxa for these variables are a reflection of the hypermasticatory trend.

\section{Further tests of the reversal hypothesis}

Based on the evidence outlined above, we believe that the reversal hypothesis has con- siderable merit at this time and support Howell and Coppens (1976) in their placement of the OMO sample in $A$. africanus. The reversal hypothesis logically evokes several predictions that may be tested against new information and may be rejected on (at least) the following grounds.

1. If a sudden change in tooth size is demonstrated among the non- $A$. boisei sample at Omo. Sample sizes are too small to test this hypothesis at present.

2. The SAG specimens are separated by thousands of miles from Omo, but Omo is relatively close to Laetoli and Hadar. If the reversal hypothesis is correct, where Omo dental morphology differs from SAG, it should differ in the direction of the earlier and later Omo non-boisei specimens (respectively assigned to $A$. afarensis and $H$. habilis) and not in the direction of the $A$. boisei specimens.

3. There should be no sudden changes in dental morphology between levels at Omo.

4. If a fossil australopithecine species is discovered from the 800,000 year gap that 1 ) does not have the hypermasticatory specializations of $A$. africanus and/or 2) is equally or more similar to $A$. afarensis and $H$. habilis than is the OMO sample, then the reversal hypothesis is disproven.

\section{CONCLUSIONS}

The analysis presented here has been a test of the evidence presented by Johanson and White (1979:328) that "dental metrics reinforce the hypothesis that the Sterkfontein Type Site and Makapansgat gracile australopithecines represent [only] a link between the basal, undifferentiated hominids at Hadar and Laetoli and later robust australopithecines" and that $A$. africanus is not an ancestor of the Homo lineage. If their hypothesis is correct, fossils in the A. afarensisHomo lineage and intermediate in time are expected to resemble $A$. afarensis, $H$. habilis, or both. However, at Omo they do not. Dental metrics therefore do not reinforce the stasis hypothesis. Moreover, the stasis hypothesis necessitates leaving an 800,000 year gap in the fossil record, and the immediate ancestor of Homo remains undiscovered. If the intermediate specimens at $\mathrm{Omo}$ are $A$. africanus, and they seem to be on the basis of tooth size, then we are left with an 800,000 year period of time spreading between $A$. afarensis and $H$. habilis during which the only "nonrobust" specimens found are $A$. africanus spec- 
imens. Therefore, on the basis of odontometric evidence, but in conjunction with other morphological evidence, we suggest that the reversal hypothesis is, at present, the strongest of the four possible hypotheses explaining the Omo fossils. In other words, since $A$. africanus is the only possible immediate ancestor of $H$. habilis yet discovered, and since the reversal required to fit $A$. africanus into the Homo lineage is not an unlikely event, $A$. africanus serves as the most likely known precursor to the Homo lineage. This evidence reemphasizes the importance of the Omo site and the urgency of future collection there and also demonstrates the necessity for a systematic and thorough analysis of these critical specimens.

\section{SUMMARY}

Several hypotheses explain the existence of a sample at Omo that odontometrically more closely resembles $\boldsymbol{A}$. africanus than any other known fossil hominid. The most parsimonious explanation for this observation is that the species at Omo is Australopithecus africanus. The presence of $A$. africanus (or the presence of $A$. africanus-sized teeth) at Omo makes it more likely than heretofore that $A$. africanus is an ancestor of later Homo species. The intimate association between the components of the masticatory complex accounts for the apparent reversal of a number of traits in the advocated $A$. afarensis- $A$. af ricanus-Homo lineage. Until counter evidence is presented, it is premature to remove A. africanus from the ancestry of the Homo lineage.

\section{ACKNOWLEDGMENTS}

We gratefully acknowledge M.H. Wolpoff for generously atrowing us use of his dental data. We also wish to thank the following for their helpful criticisms and discussions of previous drafts of this manuscript: C.L. Brace, W.H. Kimbel, A. Kramer, B. Latimer, W.R. Leonard, M.L. Robertson, B.H. Smith, R. Wikander, R. Wrangham, and L.L.A. Yaroch. The comments of three anonymous reviewers were helpful and much appreciated. Special thanks are due W.H. Kimbel and B. Latimer for their hospitality and helpful discussion. We are thankful for $K$. Guire's and E. Schneiderman's aid in statistical analysis and Teryl Lynn's execution of the illustrations.

\section{LITERATURE CITED}

Arambourg, C, Chavaillon, J, and Coppens, Y (1967) Prémiers résultats de la nouvelle mission de l'Omo. C.R. Acad. Sci. 265:1891-1896.
Arambourg, C, Chavaillon, J, and Coppens, Y (1969) Résultats de la nouvelle mission de l'Omo (2eme campagne 1969). C.R. Acad. Sci. 268:759-762.

Arambourg, C, and Coppens, Y (1967) Sur la découverte dans le Pléistocene inferieur de la vallée de l'Omo (Ethiopie). S. Afr. J. Sci. 64:58-59.

Aronson, J, Schmitt, TJ, Walter, RC, Taieb, M, TieceIin, J-J, Johanson, DC, Naeser, CW, and Nairn, AEM (1977) New geochronologic and paleomagnetic data for the hominid-bearing Hadar Formation of Ethiopia. Nature 267:323-327.

Bishop, WW, and Miller, J (eds) (1972) Calibration of Hominoid Evolution. London: Scottish Academic Press.

Blumenberg, B, and Lloyd, AT (1983) Australopithecus and the origin of the genus Homo: Aspects of biometry and systematics with accompanying catalog of tooth metric data. Biosystems 16:127-167.

Brace, CL (1967a) Environment, tooth form and size in the Pleistocene. J. Dent. Res. 46:809-816.

Brace, CL (1967b) The Stages of Human Evolution: Human and Cultural Origins. Englewood Cliffs, NJ: Prentice Hall

Brace, CL (1973) Sexual dimorphism in human evolution. Yrbk. Phys. Anthropol. 16:31-49.

Brace, CL (1977) Occlusion to the anthropological eye. In McNamara, JA (3d): The Biology of Occlusal Development. Craniofacial Growth Series Monograph No. 7. Ann Arbor, MI: Center for Human Growth and Development, pp. 179-209.

Brace, CL (1979) Krapina, "classic" Neanderthals, and the evolution of the European face. J. Hum. Evol. $8: 527-550$.

Brace, CL (1980) Australian tooth-size clines and the death of a stereotype. Curr. Anthropol. 21:141-164.

Brock, A, McFadden, PL, and Partridge, TC (1977) Preliminary palaeomagnetic results from Makapansgat and Swartkrans. Nature 266:249-250.

Broom, R, and Robinson, JT (1952) Swartkrans ape-man, Paranthropus crassidens. Transvaal Mus. Mem. 6:1123.

Brown, FH, and Nash, WP (1976) Radiometric dating and tuff mineralogy of Omo group deposits. In Y Coppens, FC HowelI, GL Isaac, and REF Leakey (eds): Earliest Man and Environments in the Lake Rudolf Basin. Chicago: University of Chicago Press, pp. 5063.

Brown, FH, and Shuey, RT (1976) Magnetostratigraphy of the Shungura and Usno formations, Lower Omo valley, Ethiopia. In Y Coppens, FC Howell, GL Isaac, and REF Leakey (eds): Earliest Man and Environments in the Lake Rudolf Basin. Chicago: University of Chicago Press, pp. 64-78.

Butler, PM (1937) Studies of the mammalian dentition. I. The teeth of Centeles ecandatus and its allies. Proc. Zool. Soc. Lond. 107:103.

Butler, PM (1939) Studies of the Mammalian dentition Differentiation of the postcranial dentition. Proc. Zool. Soc. Lond. 109:1-36.

Butler, PM (1961) Relationships between upper and lower molar patterns. Int. Colloq. Evol. Mammal. Part I. Don. Vlaamse Acad. Wtensch Lett. Sch. Kunsten Belgie, Brussels, pp. 117-126.

Butler, PM (1963) Tooth morphology and primate evolution. In DR Brothwell (ed): Dental Anthropology, London: Pergammon Press, pp. 1-14.

Butzer, KW (1974) Paleoecology of South African australopithecines: Taung revisited. Curr. Anthropol. 15:367-382.

Campbell, BG (1978) Some problems in hominid classification and nomenclature. In C Jolly (ed): Early Homi- 
nids of Africa. London: Duckworth, pp. 565-581.

Clarke, RJ (1979) The Cranium of the Swartkrans Hominid SK 847 and its Relevance to Human Origins. Ph.D. Dissertation. University of Witwaterstrand, Johannesburg.

Coppens, Y (1972) Tentative de zonation du Pliocéne et du Pléistocene d'Afrique par les grands Mammiféres. C.R. Acad. Sci. 272:181-184.

Coppens, Y (1973) Les restes d'Hominidés des series superieures des formations pliovillafranchiennes de IOmo en Ethiopie (récoltes 1970, 1971 et 1972). C.R. Acad. Sci. 276:1981-1984.

Coppens, Y (1974) Les faunes de Vertébrés du Pliocéne et du Pléistocéne ancien d'Afrique. Le congrés du Néogene méditerraneen. Communications, recommendations, conclusions. T.I. Mémoires du B.R.G.M. 78:109119.

Coppens, Y (1975) Evolution des Mammiféres, de leurs fréquences et de leurs association au cours du PlioPléistocéne dans la basse vallée de l'Omo en Ethiopie. C.R. Acad. Sci. 281:1693-1696.

Coppens, Y (1980) The differences between Australopithecus and Homo; preliminary conclusions from the Omo research expedition studies. In L-K Konigsson and F Sundstrom (eds): Current Arguments on Early Man. Oxford: Pergammon Press, pp. 207-225.

Coppens, Y (1981) Le cerveau des hommes fossiles. C.R. Acad. Sci. 292:3-24.

Coppens, Y (1983) Systématique, phylogénie, environnement et culture des australopithéques, hypothés et synthése. Bull. Mem. Soc. d'Anthropol. Paris (t. 10 série) 13:273-284.

Coppens, Y, Howell, FC, Isaac, GL, and Leakey, REF (eds) (1976) Earliest Man and Environments in the Lake Rudolf Basin. Chicago: University of Chicago Press.

Corrucini, RS, and McHenry, HM (1980) Cladometric analysis of Pliocene hominids. J. Hum. Evol, 9:209221.

Dahlberg, AA (1945) The changing dentition of man. J. Am. Dent. Assoc. 32:676-690.

Dahlberg, AA (1950) The evolutionary significance of the protostylid. Am. J. Phys. Anthropol, 8:15-27.

Dahlberg, AA (1951) The dentition of the American Indian. The Physical Anthropology of the American Indian. New York: Viking 5:138-176.

Dahlberg, AA (1963) Dental traits as identification tools. Dent. Prog. 3:155-160.

DuBrul, EL (1977) Early hominid feeding mechanisms. Am J. Phys. Anthropol. 47:305-320.

Gantt, DG (1983) The enamel of Neogene hominoids: Structural and phyletic implications. In R Ciochon and $R$ Corruccini (eds): New Interpretations of Ape and Human Ancestry. New York: Plenum Press, pp. 249298.

Gingerich, PD (1976a) Cranial Anatomy and Evolution of Early Tertiary Plesiadapidae (Mammalia, Primates). Papers on Paleontology No, 15. Ann Arbor: University of Michigan Press.

Gingerich, PD (1976b) Paleontology and phylogeny: Patterns of evolution at the species level in early Tertiary mammals. Am. J. Sci. 276:1-28.

Gingerich, PD (1979) The stratophenetic approach to phylogeny reconstruction in vertebrate paleontology. In J Cracraft and $N$ Eldredge (eds): Phylogenetic Analysis and Paleontology. New York: Columbia University Press, pp. 41-74.

Gingerich, PD, and Schoeninger, M (1977) The fossil record and primate phylogeny. J. Hum. Evol. 6:483503 .
Heinzelin, J, Brown, FH, and Howell, FC (1970) Pliocene/Pleistocene formations in the lower Omo basin, southern Ethiopia. Quaternaria 13:247-268.

Howell, FC (1969) Remains of Hominidae from Pliocene/ Pleistocene formation in the lower Omo basin, Ethiopia. Nature 223:1234-1239.

Howeil, FC (1975) Hominidae. In VJ Maglio and HBS Cooke (eds): Evolution of African Mammals. Cambridge: Harvard University Press, pp. 154-248.

Howell, FC, and Coppens, Y (1973) Deciduous teeth of Hominidae from the Pliocene/Pleistocene formations of the lower Omo basin, Ethiopia. J. Hum. Evol. 2:463472.

Howell, FC, and Coppens, Y (1976) An overview of Hominidae from the Omo Succession, Ethiopia. In Y Coppens, FC Howell, GL Isaac, and REF Leakey (eds): Earliest Man and Enviromments in the Lake Rudolf Basin. Chicago: University of Chicago Press, pp. 522532.

Howell, FC, Coppens, Y, and Heinzelin, J (1974) Inventory of remains of Hominidae from Pliocene/Pleistocene formations of the lower Omo basin, Ethiopia (1972-1973). Am. J. Phys. Anthropol. 40:1-16

Hunt K, and Vitzthum, VJ (1984) A dental metric assessment of the phylogenetic position of Australopithecus africanus. Am. J. Phys. Anthropol. 63:172.

Hylander, W (1979) The functional significance of primate mandibular form. J. Morphol. 160:223-240.

Johanson, DC (1980) Early African hominid phylogenesis: A re-evaluation. In L-K Konigsson and $F$ Sund strom (eds): Current Arguments on Early Man. Oxford: Pergammon Press, pp. 31-69.

Johanson, DC, and Edey, MA (1981) Lucy, the Beginnings of Humankind. New York: Simon \& Schuster.

Johanson, DC, and White, TD (1979) A systematic as sessment of early African hominids. Science 202:321330.

Johanson, DC, White, TD, and Coppens, Y (1978) A new species of the genus Australopithecus (Primates: Hom inidae) from the Pliocene of Eastern Africa. Kirtlandia 28:1-14.

Jolly, CJ (1970) The seed eaters: A new model of hominid differentiation based on a baboon analogy. Man 5:527.

Kay, RF (1981) The nut-crackers-A new theory of the adaptations of Ramapithecinae. Am. J. Phys. Anthro pol. 55:141-151.

Kimbel, WH (1984) Variation in the pattern of cranial venous sinuses and hominid phylogeny. Am. J. Phys. Anthropol. 63:243-263.

Kimbel, WH, Johanson, DC, and Coppens, Y (1982) Pliocene hominid cranial remains from the Hadar formation, Ethiopia. Am. J. Phys. Anthropol. 57:453-500.

Kimbel, WH, and Rak, Y (1985) Functional morphology of the asterionic region in extant hominoids and fossil hominids. Am. J. Phys. Anthropol. 66:31-54.

Kimbel, WH, White, TD, and Johanson, DC (1984) Cranial morphology of Australopithecus afarensis: A comparative study based on a composite reconstruction of the adult skull. Am. J. Phys, Anthropol. 64:337-388.

Leakey, REF (1972) Further evidence of Lower Pleistocene hominids from East Rudolf, North Kenya. Nature 237:264-269.

Leakey, REF (1973) Further evidence of Lower Pleisto cene hominids from East Rudolf, North Kenya, 1973. Nature 242:170-173.

Le Gros Clark, WE (1947) Observations on the anatomy of the fossil Australopithecinae. J. Anat. 81:300-333.

Le Gros Clark, WE (1969) Antecendents of Man. New York: Quadrangle. 
Mayr, E (1966) Animal Species and Evolution. Cambridge: Belknap.

Mayr, E (1969) Principles of Systematic Zoology. New York: MeGraw-Hill.

McFadden, PL, Brock, A, and Partridge, TC (1979) Paleomagneticism and the age of the Makapansgat hominid site. Earth Planet Sci. Lett. 44:373-382.

McHenry, HM (1983) Relative size of the cheek teeth in Australopithecus. Am. J. Phys. Anthropol. 60:224.

McHenry, HM (1984) Relative cheek tooth size in Australopithecus. Am. J. Phys. Anthropol. 64:297-306.

McHenry, HM (1985) Implications of postcanine megadontia for the origin of Homo. In E Delson (ed): Ancestors: The Hard Evidence. New York: Alan R. Liss, Inc., pp. 178-183.

Miller, RG (1966) Simultaneous Statistical Inference. New York: McGraw-Hill.

Molnar, S, and Gantt, DG (1977) Functional implications of primate enamel thickness. Am. J. Phys. Anthropol. 46:447-454

Olson, TR (1981) Basicranial morphology of the extant hominoids and Pliocene hominids: The new material from the Hadar Formation, Ethiopia, and its significance in early human evolution and taxonomy. In CB Stringer (ed): Aspects of Human Evolution. London: Taylor and Francis, pp. 99-128.

Olson, TR (1985) Cranial morphology and systematics of the Hadar Formation Hominids and "Australopithecus" africanus. In E Delson (ed): Ancestors: The Hard Evidence. New York: Alan R. Liss, Inc., pp. 102-119.

Partridge, TC (1973) Geomorphological dating of cave opening at Makapansgat, Sterkfontein, Swartkrans and Taung. Nature 246:75-79.

Rak, Y (1983) The Australopithecine Face. New York: Academic Press.

Rak, Y (185) Australopithecine taxonomy and phylogeny in light of facial morphology. Am. J. Phys. Anthropol. 66:281-288.

Read, DW (1984) From multivariate statistics to natural selection: a reanalysis of the Plio/Pleistocene hominid dental material. In GN von Vark and WW Howells (eds): Multivariate Statistical Methods in Physical Anthropology. New York: Reidel, pp. 377-413.

Reed, CA, and Falk, D (1977) The stature and weight of Sterkfontein 14, a gracile australopithecine from Transvaal, as determined from the innominate bone. Fieldiana (Geology) 33(23):423-440.

Robinson, JT (1954) Prehominid dentition and hominid evolution. Evolution 8:324-334.

Robinson, JT (1956) The dentition of the Australopithecinae. Transvaal Mus. Mem. 9:1-179.

Robinson, JT (1958) Cranial cresting patterns and their significance in the Hominoidea. Am. J. Phys. Anthropol. 16:397-428.

Robinson, JT (1962) The origin and adaptive radiation of the australopithecines. In G Kurth (ed): Evolution and Hominization. Stuttgart: Gustav Fischer Verlag, pp. 150-175.

Robinson, JT (1963) Adaptive radiation in the australopithecines and the origin of man. In FC Howell and F Bourliere (eds): African Ecology and Human Evolution. Chicago: Aldine, pp. 385-416.

Robinson, JT (1972) Early Hominid Posture and Locomotion. Chicago: University of Chicago Press.
Senut, B, and Tardieu, C (1985) Functional aspects of Plio-Pleistocene hominid Iimb bones: Implications for taxonomy and phylogeny. In E Delson (ed): Ancestors: The Hard Evidence. New York: Alan R. Liss, Inc., pp. 193-200.

Steudel, K (1980) New estimates of early hominid body size. Am. J. Phys. Anthropol. 52(1):63-70.

Tobias, PV (1967) The Cranium and Maxillary Dentition of the Australopithecus (Zinjanthropus) boisei. Olduvai Gorge, 2. London: Cambridge University Press.

Tobias, PV (1973) New developments in hominid paleontology in South and East Africa. Annu. Rev. Anthropol. 2:311-334.

Tobias, PV (1978) The place of Australopithecus africanus in hominid evolution. In DJ Chivers and KA Joysey (eds): Recent Advances in Primatology, London: Academic Press, Vol. 3, pp. 373-394.

Tobias, PV (1980) "Australopithecus afarensis" and A. africanus: Critique and an alternative hypothesis. $\mathrm{Pa}$ laeontol. Afr. 23:1-17.

Tobias, PV (1985) Single characters and the total mor. phological pattern redefined: The sorting effected by a selection of morphological features of the early hominids. In E Delson (ed): Ancestors: The Hard Evidence. New York: Alan R. Liss, Inc., pp. 94-101.

Vrba, ES (1975) Some evidence of chronology and paleoecology of Sterkfontein, Swartkrans and Kromdraai from the fossil Bovidae. Nature 254:301-314.

Ward, SC (1979) Form and Function in Primate Jaw Mechanics. Ann Arbor, MI: University Microfilms.

Ward, SC, and Molnar, S (1980) Experimental stress analysis of topographic diversity in early hominid gnathic morphology. Am. J. Phys. Anthropol. 53:383395 .

White, TD (1977) The Anterior Mandibular Corpus of Early African Hominidae: Functional Significance of Shape and Size. Ann Arbor, MI: University Microfilms.

White, TD (1985) The hominids of Hadar and Laetoli: An element-by-element comparison of the dental samples. In E Delson (ed): Ancestors: The Hard Evidence. New York: Alan R. Liss, Inc., pp. 138-152

White, TD, and Harris, JM (1977) Suid evolution and correlation of African hominid localities. Science 198:13-21.

White, TD, and Johanson, DC (1982) Pliocene hominid mandibles from the Hadar formation, Ethiopia: 19741977 collections. Am. J. Phys. Anthropol. 57:501-544.

White, TD, Johanson, TD, and Kimbel, WH (1981) Australopithecus africanus: Its phyletic position reconsidered. S. Afr. J. Sci. 77:445-470

Wolpoff, MH (1974) Sagittal cresting in the South African australopithecines. Am. J. Phys. Anthropol. 40:397-408.

Wolpoff, MH (1980) Paleoanthropology. New York: Alfred Knopf.

Wood, BA (1978) The classification and phylogeny of East African hominids. In DJ Chivers and KA Joysey (eds): Recent Advances in Primatology, London: Academic Press, Vol. 3.

Zihlman, AL (1985) A ustralopithecus afarensis: Two sexes or two species? In PV Tobias (ed): Hominid Evolution: Past, Present and Future. New York: Alan R. Liss, Inc., pp. 213-220. 